\title{
Research on Teleworking of Urban Disabled Persons
}

\author{
Ran $\mathrm{Yu}^{*}$ \\ Wuhan University of Science and Technology \\ Wuhan, China
}

\begin{abstract}
Employment of disabled persons concerns whether disabled persons can integrate into society equally, share results of social development and realize their own value and reduce the burden on family. The employment of disabled persons has important significance on themselves, family and society. At present, the main channels of employment of disabled persons include concentration in employment, employment in proportion and individual as well as flexible employment. Rapid development of the internet provides a new opportunity for employment of disabled persons. An increasing number of disabled persons work at home and create benefit through modern information and communication technology such as the internet. This article mainly analyzes how urban disabled persons realize employment or entrepreneurship at home through the internet, current situation and problems of teleworking, makes recommendations for improvement from policies of teleworking, employment environment and vocational training, in order to improve pertinence and effectiveness of teleworking of disabled persons.
\end{abstract}

Keywords—urban disabled persons; teleworking; internet

\section{TOPIC SELECTION BACKGROUND AND RESEARCH SIGNIFICANCE}

\section{A. Topic Selection Background}

Under high attention of the country and government as well as efforts of all sectors of society, the cause of disabled persons has obtained many achievements since the establishment of the nation. Living standard and employment level of disabled persons are improved. But meanwhile, the level cannot catch up with that of able-bodied persons. As a constituent part of members of society, disabled persons play indispensable role on the road of building moderately prosperous society. They are also one of them member to promote economic development and social transformation. Nowadays, the economy develops and transforms rapidly. On one hand, the economy presents the trend of rapid growth, but the results are not shared by all orders of society and groups equally; on the other hand, severe economic transformation also lets the society take risks and pay huge costs. But these costs are not assumed by people. Some vulnerable groups assume more average cost of economic transformation, especially disabled persons. In addition, disabled persons belong to vulnerable groups marginalized gradually, which make them impacted more greatly in economic changes.

However, with development of internet, scientific and technological progress and technical improvement, more and more disabled persons are fond of using internet

*Ran Yu, Master of Wuhan University of Science and Technology entrepreneurship to solve employment problems. Because living conditions and levels between urban and rural disabled persons are different, internet is more common in cities and towns. Increasing number of urban disabled persons begin to use internet to solve employment problems. In recent years, the internet develops rapidly. E-commerce is popularized. At the meantime, under the background environment of entrepreneurship and innovation of the masses, it promotes disabled persons to join in network entrepreneurship gradually. It becomes new tendency of employment development of disabled persons by using internet entrepreneurship. The uniqueness of this employment method is that employees can realize remote control at home without face-to-face contact. It provides more conveniences for disabled persons. Therefore, using internet entrepreneurship at home to drive employment gradually becomes the first choice of many urban disabled persons.

\section{B. Purpose and Significance of Research}

At present, our country is in the critical period on building moderately prosperous society. Groups in society are important part to build a harmonious society. Meanwhile, the technological development of internet changes with each passing day. Internet provides channel of employment for more and more people. It also opens a new door for disabled persons. It is feasible method at the present stage to use internet, the convenient and rapid channel to provide employment for disabled persons.

At present, the specific research on employment problems of disabled persons is limited. At the same time, there are few exploration and research on emerging employment channels for disabled persons. This article pays attention to discussing new pattern of employment of disabled persons. Teleworking of disabled persons on one hand can reduce inconveniences faced by disabled persons in employment and fully respect principal status of disabled persons in employment, on the other hand, can increase income of disabled persons. Combining teleworking of disabled persons with social employment environment can help to further expand and extend employment policy for disabled persons and improve law construction related to employment of disabled persons.

This article analyzes and researches teleworking of disabled persons and sets forth employment paths suitable for disabled persons produced and developed with social development as well as promotes and consolidates new opinion on disabled persons. Defects on mind and body let disabled persons cannot participate in social competition fairly and justly nor safeguard their own rights and interests 
completely. Besides, this article makes reference proposals to help disabled persons to realize teleworking in aspects such as government, society and family. It makes for disabled persons to improve sense of self-identification and social status and helps them to realize social value and life value of themselves. Teleworking of disabled persons is also innovation promotion for employment of disabled persons. The employment of the disabled is the most primary problem in their life. Once disabled persons have stable channels of employment, their living standard can be improved, which narrow the gap between the disabled and abled person to some extent, and then help to reduce economical burden of family for the disabled. It is also important measure to promote harmonious development of the society. However, urban and rural dual structure of our country exists for a long time and restricts the development of urban-rural integration and employment situation of urban and rural disabled persons cannot lump together, so this article mainly discusses development present situation and problem of teleworking of urban and rural disabled persons.

\section{Main Contents of the Research}

Teleworking of disabled persons mainly refers to employment pattern that disabled persons work at fixed places where they often live in daily life to produce economic benefit. Therefore, the vocational choice of teleworking is also very clear. Most have relationship with internet industry, such as maintenance crews and administrators of the internet, customer service staff and examiner for pictures on taobao website; editors and graphic designers of website. Disabled persons proficient in knowledge of website design can specialize in design and layout of website; disabled persons can open online shop and e-commerce on WeChat through capturing market requirements and realize self-employment through selling products or service on the network.

Therefore, this article mainly researches the new type employment pattern that closely links family, community and internet together. It is different from but has relationship with traditional concentration in employment, employment in proportion, individual and flexible employment for disabled persons. Teleworking pattern of disabled persons embodies flexibility of independent employment of disabled persons, but its employment channel cannot separate from social enterprises and organizations. Compared with traditional employment pattern, its employment environment is more suitable for disabled persons. The working mode and working time are more flexible and changeable. Disabled persons can realize self adjustment to a larger extent, which cannot be realized in actual employment. Therefore, as emerging employment pattern for disabled persons, teleworking is a relatively ideal employment pattern that keeps up with the development of the times and meets demands of the disabled. However, teleworking shall also conform to different disability types and degrees of disabled persons. It cannot meet requirements of employment of all disabled persons. So teleworking also has limitation. This article researches and discusses benefits brought by this employment pattern for disabled persons, development status and limitation, in order to help employment of the disabled and build more reasonable and benign network for employment of disabled persons.

\section{PRACTICAL PROBLEMS EXISTING IN TELEWORKING OF URBAN DISABLED PERSONS}

\section{A. Objective Factors of Disabled Persons}

The teleworking of urban disabled persons reduces practical difficulties and psychological barriers of disabled persons to some extent because of the promotion of internet. For example, they do not need to communicate with others face to face. Remote communication reduces inconveniences and makes them complete the operation more conveniently and faster. But in practical operation, disabled persons still face many practical inconveniences and difficulties.

Firstly, because of physical disabilities, compared with able-bodied person, disabled persons have fewer opportunities of employment. Different disability types lead to the situation that the type of work for disabled persons is also limited. Types of disabled persons of teleworking discussed in this article mainly include the disabled without disability in intelligence, eyesight and mind. Because it is very difficult for people with disability in intelligence, mind and eyesight to take care of themselves in daily life, it restricts employment of them.

Secondly, the cultural quality and level of education of disabled persons are generally low. Their vocational skills cannot meet employment demands under the mechanism of fierce talent competition. Besides, they cannot get the diploma recognized by the society. It is also difficult for them to master technology really required in labor market. The series of domino effect will hinder disabled persons to find ideal and matched work.

Besides, compared with able-bodied persons, disabled persons have certain mental defects because of being influenced by the body. In general, the cognitive understanding and response of disabled persons is slower than able-bodied persons. They have poorer ability to communicate with others, comparing with able-bodied persons. It shows that they are self-abased and not self-confident, afraid to contact with others, and have excessively pessimistic attitude toward life; some disabled persons do not correctly recognize their physical defect and job orientation. They have grandiose aims but puny abilities, love ease and hate work and seriously want to reply on others; some disabled person desire for fairness blindly, do not positively improve state of themselves and would like to accept relief rather than ask for help actively. These sensitive and complicated mental activities hinder positive employment of disabled persons to a certain extent.

\section{B. Limitation of Teleworking of Urban Disabled Persons}

Although teleworking is a new type employment pattern for disabled persons to make a living, but it needs improvement. That is to say, teleworking of disabled persons has many defects that restrict measures took by disabled persons to use the internet for self-dependence. 
Firstly, disabled persons face limitation of funds. As an industry of emerging development, the internet develops very fast, but it still needs material conditions and operating skills as support. The basic condition of teleworking is to use computer skillfully and make the best of network resources. Disabled person shall have basic material conditions such as computer and network as well as proficient operation techniques. But in real life, because of insufficient fund, low income level and inadequate social insurance, family burden is heavy. Disabled person do not have enough circulating fund to buy computer or basic products for internet entrepreneurship. It seriously restricts sustainable and sound development of teleworking.

Secondly, disabled person lack basic educational training of network employment. Compared the able-bodied person, disabled person have limited level of education and their cognition for new things is backward. They lack understanding for emerging post of network employment and do not know how to operate. Their cognition and application level for the internet is at the initial stage. They have low skill level and poor ability to adapt to market change. Mastering of knowledge and timely update is backward. Most only know channels of traditional employment and have no in-depth understanding for internet, so they are unqualified to use the internet to work. Assistance from the society for disabled person is easy to become formalistic and mainly focuses on guidance of public opinion as well as gives encouragement and support mentally, but it lacks related courses and popularization of employment knowledge aiming at network employment training for disabled persons.

Thirdly, family is the foundation for teleworking of disabled person. Concern and support from family member play a crucial role in teleworking of disabled persons. Disabled persons make economic burdens of the family heavier, so most families avoid risk, namely not to form superfluous economic attrition. According to financial situation of the family, some family members of disabled person do not understand internet employment and hold hesitant or opposed opinion on teleworking on the internet for disabled person. Most of them look at posts of physical labor and are not familiar with network position that can produce economic benefits through remote operation. Therefore, some disabled persons cannot get support because of misunderstanding. It is extremely unfavorable for sound development of teleworking of disabled persons.

\section{ANALYSIS AND COUNTERMEASURES ON TELEWORKING OF URBAN DISABLED PERSONS}

\section{A. Fully Exert Main Responsibilities of the Government in Teleworking System and Intensify Support}

1) Strengthen rehabilitation of disabled persons to make them more actively participate in teleworking: Principal factor that influences employment of most disabled persons is physical defects. Unlike able-bodied persons, they are unqualified for corresponding operating post. Government shall bear the main responsibility in rehabilitation. The rehabilitation of disabled person is the problem that needs to be solved urgently and long-term adherence for vulnerable groups such as disabled person, comparing with other vulnerable groups. Government shall gradually improve the concept of rehabilitation, focus on precaution from physical rehabilitation to psychological rehabilitation and broaden contents and width of rehabilitation as well as improve physical and mental quality of disabled persons. In addition, the government shall detail construction of rehabilitation project, increase input and actively promote research input and result transformation for rehabilitation of disabled persons, make disabled persons realize better rehabilitation with the help of achievement in scientific and technological development and promote teleworking with rehabilitation.

2) Complete and perfect policies and regulations related to teleworking of disabled persons: Law-based governance is the basic strategy to govern the country. Social progress at different levels cannot do without guarantee of law. Perfection of legal construction for employment of disabled persons helps to protect basic rights and interests of disabled persons and promote development of teleworking of disabled persons. Meanwhile, it is important symbol for progress of social civilization. Teleworking of disabled persons relying on the internet is merging employment pattern. So far, there aren't clear related laws and regulations to standardize and protect the operation. Legislation related to employment and social insurance for disabled person is relatively backward. Therefore, the government shall promote development of legislation related to disabled persons and perfect relevant legislation of teleworking of disabled persons.

3) Increase preferential policies and capital investment in teleworking of disabled persons: The internet is equal. It makes all of us get information and service with the same technological means and the same way. The government shall give full play to human resources and social insurance and promote development of teleworking of disabled persons, intensify financial support and implement preferential policies such as reduction or exemption of tax, project subsidies and credit aid, perfect social security system, enlarge coverage area of policies and provide public service guarantee for teleworking of the disabled. Meanwhile, comprehensively use administrative, economic and legal means and improve environment for teleworking of disabled person through various channels as well as establish efficient, unified and ordered service system of teleworking.

4) Strengthen education and vocational training and make the most of modern information technology: Internet, the equal platform is of profound significance for employment of disabled person. If they can learn to surf the internet, use the computer and make phone calls, it is possible for them to realize employment in network era. Disabled persons can participate in industries that develop through the internet such as online shop and outsourcing business and realize teleworking by staying at home. The government shall increase input in training funds for special network employment education of disabled person, make the best of 
training bases for vocational skills of disabled person, strengthen course development for network employment and entrepreneurship of disabled persons, encourage social training institutions with good economic condition to participate in, hold various kinds of professional training courses and comprehensively improve ability of disabled persons in internet employment.

\section{B. Encourage Social Forces to Support Teleworking of Disabled Persons}

1) Establish new concept for the disabled and employment attitude of disabled person: Equality, participation and sharing are concepts for the disabled of modern civilization. The establishment of new concept for the disabled and employment attitude of disabled person needs positive participation of all members of the society. It is necessary to make the best of multimedia tools such as internet and broadcast and guide people to treat employment of disabled person equally and friendly and treat the disabled correctly, realize advantage and potential of disabled person, vigorously advocate typical cases of teleworking of disabled persons, and encourage more disabled persons to join in teleworking, let more social forces to participate in teleworking of disabled persons and undertake social responsibilities to help the disabled.

2) Social organizations increase assistance for teleworking of disabled persons: The organization to assist employment of disabled persons is single. The leading of government cannot completely solve employment problems of disabled persons. It needs the support of social organization. Disabled Persons Federation (DPF) is unified organization of disabled persons. It bases on the disabled and has natural consciousness and the mission to serve disabled persons. DPF shall play a role in employment system of disabled persons, pay high attention to teleworking of disabled persons and strengthen consciousness and initiative. Besides, DPF should establish assistance system, serve disabled persons and keep in close touch with disabled persons, know material problems and difficulties of teleworking of disabled persons and actively give a hand aiming at specific problems.

3) Actively give play to important role of community in teleworking system of disabled person: Teleworking of disabled persons cannot do without assistance and support of community. With devolution of administrative power to lower levels of the government, community plays a more important role in supporting of teleworking of disabled persons. Community can take advantage that they can keep in close touch with disabled persons, know requirements of disabled persons in detail, personal characteristics and ability, establish personal file, cooperate with DPF and provide basic information support for rehabilitation, vocational training of disabled persons and other service management. In activities of teleworking of disabled persons, community can know employment demand and difficult points of disabled persons directly and support the disabled instead of ignoring actual requirements of teleworking of the disabled and "going about several tasks at a time".

\section{The Familyof the Disabled and the Disabled Persons Develop Abilities and Highlight the Value}

Teleworking of disabled persons complete the operation and work at home in most of the time, so teleworking is inseparable from family for the disabled. Assistance and support of family members for disabled persons greatly influence feasibility of teleworking of disabled persons. As strong supporter of disabled persons, family members shall correctly realize personal value of the disabled, let them find sense of belonging and self-esteem at home and help the disabled to regain confidence, actively encourage the disabled to carry out teleworking. Disabled persons shall endeavor to improve cultural literacy and vocational skills, establish selfconfidence and discover strengths, dare to face problems and realize active employment. In addition, disabled persons shall improve levels of knowledge and skill continuously, make up for deficiencies through merging employment channels, and rebuild social status, actively use resources to improve personal value, and then ease family burden and burden on society as well as construct harmonious society together.

\section{REFERENCES}

[1] Lai Desheng, Liao Juan, Liu Wei. Analysis on Employment of Disabled Persons in Our Country and Its Influence Factor [J], Journal of Renmin University of China, 2008 (1)

[2] Lian Chuande, Luo Qiuyue, Xu Guihua. Current Situation, Problems and Suggestions of Internet Entrepreneurship and Employment of Disabled Persons [J], China Market, 2014 (12).

[3] Shi Danxi, Wang Qi. Analysis on Changing Tendency of Employment Situation of Disabled Persons [J], Disability Studies, 2013 (4).

[4] Zhang Jianwei, Hu Juan. Achievements, Problems and Promotion Measures of Employment of Disabled Persons of China [J], 2008 (2). 